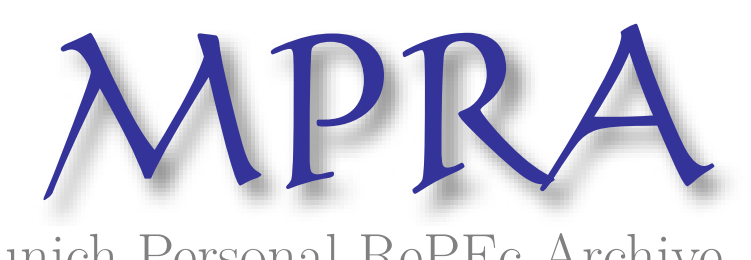

Munich Personal RePEc Archive

\title{
CONTEXTUALIZING LOCAL ECONOMIC DEVELOPMENT FOR DEVELOPING COUNTRIES
}

Hasan, Lubna

Pakistan Institute of Development Economics

1998

Online at https://mpra.ub.uni-muenchen.de/7959/

MPRA Paper No. 7959, posted 29 Jun 2008 02:23 UTC 


\title{
CONTEXTUALIZING LOCAL ECONOMIC DEVELOPMENT \\ FOR DEVELOPING COUNTRIES
}

BY

LUBNA HASAN1

\begin{abstract}
This paper explores the prospects of success of 'Local Economic Development' (LED) for the less developed countries. The concept had much success in the context of the developed world. The less developed countries, however, present a scenario where power and social structures present a challenging task for LED to be effective.
\end{abstract}

Key Words: Local Development, Decentralization

JEL Classification: R11, H77

\section{INTRODUCTION}

The concept of Local Economic Development (LED) emerged on the development forum in the late 1970s, and emphasizes a fundamental shift in the actors involved in the development process (Blakely 1994). Much has been written about the concept, and it has taken as many meanings as the number of

\footnotetext{
${ }^{1}$ The author is Research Economist at The Pakistan Institute of Development Economics, Islamabad.
} 
people writing about it. So a kind of vagueness surrounds the term. Suffice is to say that it seeks involvement of local actors ${ }^{2}$ in a process whereby they engage in stimulating economic activity of an area using its local resources (human, capital, natural and institutional). The underlying idea is to make a region as independent as possible from the national and international economies (ibid). The idea essentially revolves around harnessing the strengths of an area and furthering it with a view to enhance the competitiveness of the locality vis-à-vis rest of the world. In this sense LED envisages the process of development as an essentially endogenous process, with reliance on local resources. The concept has not only persisted but has gained in importance and application since then.

Failure of regional policies, in correcting regional imbalances, increased internationalization of the economic activity, increased mobility of the investment, and the bureaucratic government rendered local economies unstable. Response was to provide an antithesis to these factors. It was from here that the idea of LED crystallized (Eisenschitz \& Gough 1993, pp 5-11).

\section{ITS RELEVANCE FOR THE DEVELOPING WORLD}

Although the idea of LED originated in the western world, it has found its way into the developing world as well, but with a slightly different tone. Since a large number of people living in the developing region, especially in the least developed countries, live below or around poverty line, the major objective of any development intervention has to keep the target of poverty alleviation in mind. Therefore, local economic development (LED) programs have to be geared toward that end as well.

Experience of many decades has revealed that the fruits of growth were

\footnotetext{
${ }^{2}$ The term local is equally ambiguous and no single definition of the term exists. For the purpose of the present analysis local means sub-national actors (Local governments, community based organizations
} 
not distributed equally, and a large segment of population saw themselves being marginalized in the process of increasing overall welfare. Failure of the "trickle down" hypothesis had raised voices of dissent against the received wisdom. It was this disenchantment with growth that paved way for a more meaningful concept of development. Keeping the flexibility of the concept intact, It could be said that development requires an increase in the over all welfare of the society and has the objective of equity and distribution added to that of the growth. Moreover, given that growth does not filter down to lower strata of the society, the current thinking advocates for government intervention to tackle this problem.

But, how do we define poverty. Literally taken, poverty is a state of dispossession. But this physical representation of the phenomenon is not enough. Equally important are the intricate social processes that work against and accentuate this situation of dispossession. Poverty does not only mean lack of resources but manifests itself in the lack of access to basic social services such as health, education and other amenities (clean drinking water, sanitation etc.). Also, worth mentioning is the fact that poverty does not only mean lack of income earning opportunities but it a situation where certain groups are denied access to these opportunities. So, poverty, it is said, is a social phenomenon. Therefore, current approaches to poverty eradication extend the policy prescription from mere provision of employment opportunities to broader objective of provision of basic social amenities (e.g. Habitat improvement programmes). "There is consensus that achieving this objective requires progress on broad based growth, basic social services, and social safety nets" (Aturupane, Glewwe, and Isenman 1994, p 244). Both the World Bank (WB) and the United Nations (UN) advocate interventions that raise the living standards of the poor (ibid, p 244).

Given that state intervention is necessary, the question of how this 
intervention is effectuated remains there. The World Bank experience in this regard shows that chances of success of poverty alleviation programme increase if the institutions provide for popular participation, local leadership and decentralization of authority (c.f. Vorathepputipong 1988, p 392).

So, how do we gauge the prospects of success of LED for the developing world? Especially, how do issues of democratization and decentralization, which may not figure much in case of the developed world, affect the approach of LED in the developing world? In other words, is LED relevant for the less developed world, where democracy has not taken roots and decentralization is still a far cry?

\section{LOCAL ECONOMIC DEVELOPMENT- PROSPECTS FOR SUCCESS}

An analysis of the prospects of LED in the developing world should begin with the analysis of the underlying structure of relations among the various actors involved in the process. It is important to study these structures since they determine the ongoing social and political processes. These processes, in turn, influence the effectiveness of LED measures. The success or otherwise of LED measures is "rooted within a range of local non-economic factors such as local community, culture and politics" (Syrett 1995, p 308).

Since the overriding concern of the LED approach is with the actors at the local level it is appropriate to begin with analysing the relation between the local government and the local people. The important question to ask is how far the local government represents the interest of the people. Here, two scenarios could be visualized. First, democratic participation represents the interests of majority of people (broad based) and is not dominated by any particular class. And, alternatively, we could have a scenario in which a particular class dominates the political atmosphere and the decision making process.

Further, despite rhetoric of decentralisation, the central government 
continues to occupy an important and influential position in the whole set up. As Syrett puts it, "the historical legacy of non-democratic political system reliant on political clientelism and state repression means that the state...continues to retain its position as a key source of social power" (Syrett 1995, p 72)3. In most of the developing world countries we notice that a dual system of governance exists where even though the decision making power rests with the elected officials, the administrative set up is still under the control of the central government. Governors are the central government appointees. Higher-level administrative staff is also appointed by the central government. This means that the central government still retains some control over local level.

So equally important is the issue of local-center relations. It should determine the extent of political autonomy of a particular local government, which, to a large extent, is said to be the result of historical formation (c.f. Syrett 1995, p72). It is reasonable to expect that different the local government will differ in the amount of the political autonomy they have varying from tight political control by the central government to a relatively politically independent local government ${ }^{4}$.

The main actors in the process are, certainly, the politicians, the administration and the community. A few comment about their interest and behaviour. (1) politicians have a short time horizon and make decisions that would bring benefits to them in shorter run, (so that their chances of being reelected are strengthened) ignoring the long term problems/potentials of the locality. Similarly, bureaucrats have their own self-interests, more committed to their own career success (Blair 1994, pp 34-36). Logically, they have their loyalties for the higher command at the center.

\footnotetext{
${ }^{3}$ Although Syrett's analysis refers to the Southern Europe, it holds application in the developing world.

${ }^{4}$ This bifurcation of analysis is influenced by Gurr and King (c.f. Syrett 1995, p 72) who argue that the capacity of a local government to successfully initiate a process of LED can be examined in a two dimensional representation of its relationship with (1) the local population and (2) the central government.
} 
Coming to the communities, nothing can be said about their behaviour with certainty. A lot depends upon the culture and on traditions. Some areas have strong bonds of community and civic sense than others. Some localities have a good experience with community action, other don't. Cultural homogeneity helps in the organization of communities. Given that politicians and bureaucrat seek self-interests, well-organized communities can be instrumental in putting a check on them, ensuring that interests of the community are not put at stake. And where the communities are not well organized NGOs can play a significant role in economic, social and political organization.

So social and political processes in combination with the behavioural patterns determine the chances of success of LED.

Coming back to the issue of the political autonomy, it is important since it determines the capacity of the local government to take suitable actions for LED, independent of the political influence of the central government. The question of participation determines the extent to which interests of different groups will be considered and taken care of and, therefore is important from the point of view of poverty alleviation programmes.

The alternative scenarios discussed above can be presented in a two dimensional graph $^{5}$.

5 This presentation of a multidimensional and complex issue is a gross oversimplification of the problem but it does serve as a useful starting point. It is in no way implied here that these two conditions are necessary and sufficient for success of LED. 


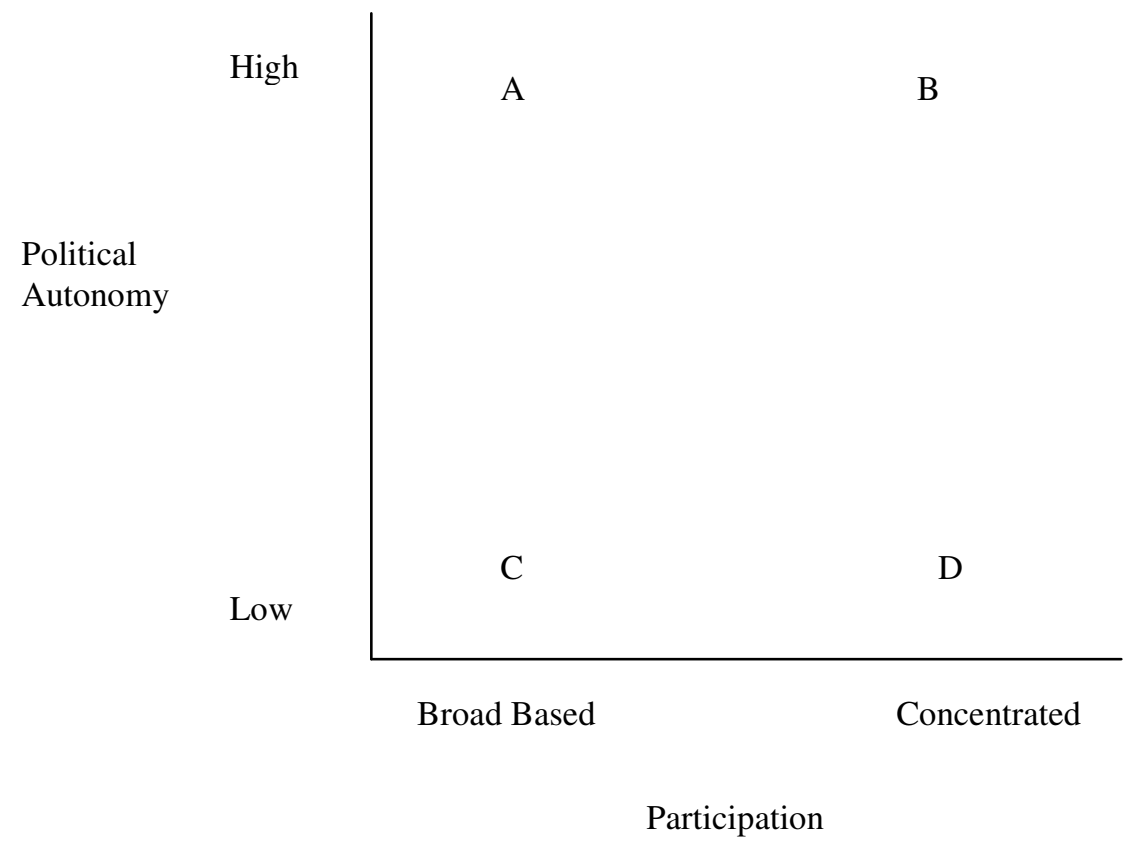

A high degree of autonomy is conducive for LED so chances of success of LED improve as we move up along the vertical axis from low to high autonomy. Moreover, broad based participation is important for achieving the goal of poverty eradication, so accomplishment of this goal becomes more feasible as we move from concentrated to broad based participation.

Based on this we conclude that point "A", which represents broad based participation and high autonomy, presents the most hopeful scenario for the twin objective of LED and poverty alleviation. A high degree of autonomy with decision-making power concentrated in the hands of few (point B) offers scope for growth but little hope for poverty reduction. In the case of low political autonomy (C\&D) LED offers little hope.

Next comes the important issue of financial autonomy and it adds another dimension to the problem. It is believed that a high degree of financial autonomy offers a local government more room for maneuverability, which is only logical, and, therefore, increases the chances of success and vice versa. 
Another important and contributing factor is the management skills of the local government. While political process determines how efficiently decisions are made, management skills determine the efficiency with which they are implemented.

Given these, what would be the impact of decentralization under various scenarios? Decentralization requires an upside down working of the state i.e., giving power to those below the state. It is favoured on the grounds that it leads to a more responsible and relevant government. Different regions have different conditions and requirements. The local governments, since they are closer to the people, it is argued, are more responsive to the needs of the people. Also, it is considered an important precondition for poverty alleviation.

Decentralization would be more effective in situation "A" (broad based \& high autonomy). In situations where power is concentrated in the hands of few (B \& D ) decentralization loses much of its appeal, and hence logic, since decisions taken will represent the interests of the politically dominant class and may even strengthen the existing structure of dominance. That is why it is suggested that for decentralization to work effectively a system of accountability should accompany it.

In situation of low political autonomy the effectiveness of this measure is uncertain. We can come across a situation where interests of the local government and the central government clash and a situation of conflict emerges. Political differences tempt the central government to create hurdles in the normal functioning of the provincial government, with an aim to reduce their effectiveness in delivering goods.

We could alternatively visualize a situation where both the local government and the central government have a consensus. The central government may take interest in the development of a region to win political support. Citing an example from Pakistan, the central government needs the support of elected members from FATA (Federally Administered Tribal Areas) 
to maintain majority in the National Assembly, and therefore grants political favours to them. In the end, financial autonomy and management skills enhance the effectiveness of decentralization and their absence does the opposite.

Coming to the question of resource flows from the central government, we can divide these resource flows into two components. (1) regular flows worked on the basis of a formula to divide resources among different regions, (2) special funds allocated under special programmes to boost up the economy of a particular region.

First type of flows should be neutral in their effect since they are decided on the technical basis. It is the second type of flows that are of particular interest. First thing that should be kept in mind is that these are usually political decisions taken to give political favours. Given this, a lot then depends upon the political autonomy of the local government. The LED approach propagates an active role of the local government in the identification and implementation of projects since it is more aware of the needs of the area. A relatively autonomous local government will be free in its choice of projects. Again if the participation is broad based, the chances are that those projects will be selected which are beneficial for majority of citizen. The success of these projects depends upon the management skills of the local government. So, we see that those localities will benefit more from resources coming from the central government that have relative political autonomy and have broad based participation. Absence of these preconditions means reduced effectiveness of this measure. And the locality is likely to encounter the same problem as it did in a top down approach to development (identification, implementation problems, political influences etc.).

Effectiveness of the local initiative is determined by the political process and how well this represents the interests of the citizen. We can identify two factors that influence initiatives. (1) level of interest, (2) level of organization. A highly interested group is more likely to influence the decision of the local government than a group of moderately interested people. Moreover, it is less 
cumbersome and costly for individuals represented by existing and organized institutions to influence decisions compared to unorganized individuals (Blair 1994, p 177).

From here we can conclude that a well-organized group with special interests is more likely to influence the local government's decision than an unorganized and moderately interested group. So those projects/decisions have greater chances of implementation where benefits accrue to an organized and influential group than those where beneficiaries are politically unorganized and less influential.

Moreover, projects that bring in immediate and significant benefits (e.g. set up of a big industrial unit) are more likely to be accepted than small investment projects of social services provision to the less advantageous group of citizen.

Even in those cases where participation is broad based (i.e. represents the interests of the majority) these two factors play a crucial role. A locality which has well organized citizen committees at the community level and, equally important, a high degree of political awareness is certainly in a better position to claim assistance, as a matter of right, than an unorganized community. Because if there are gaps in the flow of information, which is normally the case, then a local government may not have information and knowledge about the needs and requirements of each and every community.

To sum up, we conclude that those localities stand better chance of success of LED where the local government represents the interests of the majority of the citizen, has a considerably high degree of autonomy (political, decision making and financial), has sufficiently organized communities and along with all this management skills to run the whole affair. In contrast, those regions where power is concentrated in the hands of few, the local government has limited autonomy, communities are not well organized and management skills are low offers limited chances for the success of LED and poverty alleviation. Off course, 
these are not the only two scenarios that could be envisaged. These different factors can exist in any number of combinations and multiple alternatives could emerge. So the implication of all this is that as different localities will have these factors in varying degrees and combination, each will offer different possibility for the success of LED.

Of course, we cannot argue that given the best possible scenario, as discussed above, the success of LED is ensured. Indeed, suitable social and political conditions facilitate the process but there is a whole array of other factors that determine the capacity of a particular region in carrying out successful LED initiatives. Together, these factors determine the endogenous strength of a locality. So a brief review of these factors is necessary.

Resource endowment of a particular locality is certainly one such factor. These resources include human, capital, natural and institutions.

Human resources determine the potential of a locality to turn opportunities into realities. In this regard a skilled labour force is an asset for an area. Other important factors along with the skill level are the work habits and the attitudes, determined largely by historical traditions, and adaptability of the work force. A flexible work force able to adapt to changing environment is conducive for development (Blair 1994, p 142).

Related to this, another important factor is the existence, or lack, of entrepreneurship. Entrepreneurship may be defined as the capacity to identify and implement initiatives. Entrepreneurial culture varies from one region to other. Not much can be said about the factors that contribute to its development. The importance of risk taking and creativity and the presence of role models and family backgrounds and opportunity structure are among the cited factors (ibid, $\mathrm{p}$ 140). A region rich in this culture offers better prospects.

Of late, the importance of infrastructure in the process has been increasingly realized. Infrastructure is described as the "wheels" that move the engine of growth. A region well stocked with infrastructure will fare better. Stock 
of natural resources is equally important. So is the presence of well functioning institutions.

Enterprise occupies a central place in the local development programme. Small and medium enterprises are usually more "local" in their origin and are less footloose. So their presence, in large numbers, increases the resilience of an area against economic shocks.

Above all continuity of process is very important. Political disruptions, frequent transfers of the government officials hamper the process.

These are some of the factors that determine the strength of an area, and its potential for development.

\section{CONCLUSION AND COMMENTS}

LED approach dethrone the process of development from higher echelons and places it at the level where should be, i.e., the local. Its success is heavily conditioned by the presence of an overall suitable atmosphere that is determined not only by the economic factors but also by social and political processes. To the extent that localities will have the presence of these factors in varying degrees and strengths, a multiple of situations will exist. This heterogeneity of environment implies different prospects for different localities. But internal environment is important only in determining the potential of a locality. Successful realization of this potential depends upon opportunities offered by the external environment, and, hence, is not within the control of a particular locality.

Therefore, identification of this strength does not ensure development. What it does provide is a direction in which localities should work to enhance their prospects for future growth.

Moreover, Growth does not ensure poverty eradication. For that concerted actions and intervention by the government is required. Another condition, to 
make sure that the measures taken by the government do in fact reach the poor, is the existence of social consciousness and organization at the community level. But this condition, particularly with reference to the developing world, can be described as an exception, so some kind of mechanism is needed to mobilize the poor. NGOs, in this regard can play an important and significant role.

Secondly, poverty is multifaceted and, therefore, needs to be attacked from more than one front. Worth mentioning is the social alienation of the poor, denial of access to decent living. Social values are hard to change, especially of those who are in a privileged position and have command over resources and feel no need for change. The only way out for the poor is their self-organization and social and political consciousness ... empowerment. Without this slogan of democracy, autonomy and participation become meaningless.

\section{References}

Aturupane, H., P. Glewwe., and P. Iseman (1994) Poverty, Human Development and Growth; An Emerging Consensus. AEA Papers and Proceedings, 84:

Blair, J. P. (1995) Local Economic Development: Analysis and Practice. SAGE Publications. Thousand Oaks.

Blakely, E. J. (1994) Planning Local Economic Development: Theory and Practice. SAGE Publications. Thousand Oaks.

Eisenschitz, A., and J. Gough (1993) The Politics of Local Economic Policy: The Problem and Possibilities of Local Initiative. Macmillan Press, Hampshire.

Vorathepputiong, T. (1988) Decentralization for Rural Development in Thailand, in Bhatt et al (eds) Building from Below: Local Initiatives for Decentralized Development in Aia and Pacific. APDC, Kuala Lumpur.

Syrett, S. (1995) Local Development: Restructuring, Locality and Economic Initiative in Portugal. Avebury, Aldershot. 